\title{
Toward making 'IMEs' independent
}

\author{
George V Rossie PhD, R Daun Gretzinger BA
}

$\mathrm{T}$ he complaint that 'independent medical examinations' (IMEs) initiated by insurance companies are unfair or biased appears to be universal. Many claimants and their medical providers believe, perhaps with good reason, that insurance adjustors send claimants to examiners who can be counted on to issue reports that favour the insurer's position. Doctors who routinely side with insurers can expect appreciable income flow from the potentially unlimited supply of referrals.

In Colorado, several auto insurance companies consistently relied on a handful of notoriously biased doctors to perform IMEs, to the extent that the results were so predictable that the report did not have to be read to know that benefits would be terminated. For example, one well-known psychiatrist who happened to sit on the board of directors of a major insurance company once evaluated over 200 consecutive patients diagnosed with organic brain injuries from motor vehicle accidents (MVAs) without ever finding a case of emotional or intellectual problem that he could attribute to the MVA. The bulk of the patients were labelled 'malingerers' or described as having 'pre-existing psychiatric disorders'. This included one young man who had crashed his motorcycle into the side of a truck and lay in coma for two weeks. His subsequent problems of impulse control and impaired reasoning were attributed by the IME doctor to the patient having grown up with an alcoholic father!

Fed up with such abuse, a grassroots effort to reform the way that IMEs were used in Colorado sprang up, spearheaded by a state senate legislative aide who had been 'revictimized' by an IME following her own MVA. Declared to be no longer in need of treatment despite being unable to perform her routine legislative duties, she was able to garner the support of her therapists and her legislative colleagues in the State Senate to draft a bill that would prohibit any insurance company from relying on any IME to terminate MVArelated benefits. Before the bill's introduction into the State Legislature, the providers involved in her care, including physical therapy, chiropractic medicine, dentistry, neuropsychology and speech pathology, mobilized their colleagues by encouraging them to write or call their own state representatives to alert them of the problem, and asking the colleagues to alert other professionals and victims of IMEs of the effort and the process. The initial attempts by the insurance industry to kill the bill were blocked because by that time legislators from all over the state had been barraged by doctors and patients who wrote or called expressing their support for IME reform, and the bill was allowed to proceed to the committee stage for public hearings. The organizing therapists then began enlisting MVA patients to show up for the hearings to tell their stories of how they had been treated by their insurers. The response was overwhelming to the point that one critical hearing had to be moved out of the normally used hearing room into an assembly hall to accommodate the overflow crowd. Faced with this massive show of opposition, the insurance industry dropped its outright resistance and agreed to work on compromise legislation that they proposed would "dispel the misperception that the IME process was biased".

The resulting legislation, which was passed and signed into law in 1996, made several important changes to Colorado's no-fault law. First, a new program was created under the direction of the State Insurance Commissioner to provide the exclusive mechanism for resolving disputes over the reasonableness, necessity and relatedness of treatment following MVAs. The program (the Personal Injury Protection [PIP] Examination Program) makes available a group of licensed health care providers, experienced in the treatment of MVA issues and actively engaged in clinical practice, who have not earned more than half their income or spent more than half their professional time performing IMEs, to examine patients when a dispute with the insurance company arises. When a dispute arises and an examination is requested, a list of five qualified practitioners in the same specialty as the treating doctor whose opinion or bills are disputed is prepared and within five days of the request sent to the party disputing the claim (usually the insurance company, but maybe the patient in the case that there was a dispute over an earlier IME). If neither side can agree on one person from the list to conduct the examination, the insurer and the patient each strike two 
names and the remaining practitioner performs the examination. The examiner is required to address in a written report the issues in dispute, and the insurer is required to pay the benefits if the examiner agrees with the previous treatment rendered or with the medical conclusions of the treating doctor. If either party is dissatisfied with the findings, that party may request and pay for a second IME under the same procedures of selection. In this case, the conclusions of two of the three practitioners (the two examiners and the treating provider) are binding. The examiner must physically examine the patient and review the records, which must be supplied by the insurance company. The patient may augment the records as necessary. The requesting party is obligated to pay the examiner's fees. The whole process is designed to be completed within 45 days of when the insurer initially disputes the claim.

The legislation also allowed the Insurance Commissioner to contract with an outside source to create and run the program using money from a yearly fee assessed against all auto insurance companies doing business in the state. Through the normal state bidding process, IME Administrators, LLC, contracted with the Division of Insurance for a flat, fixed yearly amount, to administer the program, create the provider registry, process the requests, establish the reporting standards, train the panelists and prepare the lists of five examiners. To accomplish this, IME Administrators first recruited over 1100 medical providers in approximately 25 specialties, including chiropractors, physiatrists, orthopedists, surgeons, psychologists, dentists, optometrists and others from throughout Colorado to serve on the panel. A detailed list of biographical and practice information was gathered from each provider, and these data were entered into an automated database that was able to generate the list of five providers from the county or general vicinity in which the patient resides, in the same specialty as the treating doctor whose care was disputed. The database automatically produces a 'dossier' on each of the five candidates, incorporating the extensive educational, business and personal information already supplied by each recruit; that information is sent to the insurer and the patient to aid in making the appropriate selection of the best candidate to perform the examination. The automated database 'revolves through' all available blocks of five members of the specialty within each county, then randomly assigns the names and creates new blocks of five, as the demand for examinations dictate, so that the same five examiners are not always paired against each other. The program administrator monitors the flow of the examination process and tabulates the outcome of the examinations in terms of conclusions, costs and time to completion. The proprietary automated database then produces summary reports regarding the utilization of the program. The Commissioner of Insurance has recently awarded the management contract to a new administrator, but the process remains the same.

The PIP Examination Program went into operation on January 1, 1997. By March 1, 2000, over 10,000 requests for
IMEs had been processed. Approximately $80 \%$ of the IMEs completed to this point, for which summary data have been returned (approximately half the total conducted), indicate that the prior treatment rendered or the medical conclusions of the treating provider were reasonable, necessary and accident related. Approximately 16\% found that the care was only partly reasonable, necessary or accident related, and generally in those cases an apportionment was made. Fewer than $4 \%$ found that the care was not reasonable, not necessary or not related to the accident at all. About $12 \%$ found that the claimant was or had been disabled from work. At least $60 \%$ of the IMEs found that the claimant was in need of additional services beyond what had been provided.

For the most part, the response to the program from patients, attorneys and treating doctors has been overwhelmingly positive. Insurance company response has been less enthusiastic but still positive. Major complaints centre around their opposition to the 'same specialty' review requirement, especially when chiropractors are involved (the vast majority of disputes arise over chiropractic treatment). Most insurers strongly favour allowing medical doctors, especially physiatrists and orthopedists, to review any treating doctor's work, regardless of the specialty. Obviously, the other independently licensed practitioners oppose this type of oversight. Also, there have been some complaints of overcharging for the examinations and some unsuccessful efforts to establish a uniform fee for IMEs. Finally, some conflicts have surfaced when the patient has multiple providers from various specialties, and the insurer or the patient does not want to pay for or undergo multiple IMEs. Each year, the insurance industry has introduced legislation designed to 'dilute' the program, which to date has been unsuccessful. Despite this, there is broad consensus that the process is an inherently fair one, and the frequency of suits against insurers alleging bad faith breach of contract is reportedly drastically down in Colorado. To date, there has been virtually no 'second guessing' of the IME by patients, attorneys or insurers, any of which could demand a second examination when the results are not in accordance with their expectations, and almost no cases in which the patient has failed to cooperate with the examiner. Fears that examiners would abuse their discretion by 'retaliating' against insurance companies have not been borne out. It appears that many treating doctors have become more conscientious in their record keeping and their treatment planning, knowing that their work may be evaluated by a competent peer.

IME Administrators, LLC, believes that the process that it has created could be successfully exported to many other geopolitical settings and could be applied to any situation in which an insurer requires an independent medical examination, including worker compensation injuries, general medical conditions or disability cases. The principal rate-limiting factor in its application to other conditions is strictly political. It appears that the process, the technology and the philosophy for providing truly 'independent' IMEs do exist. 


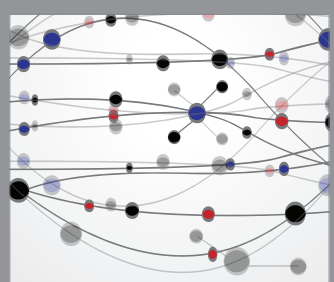

The Scientific World Journal
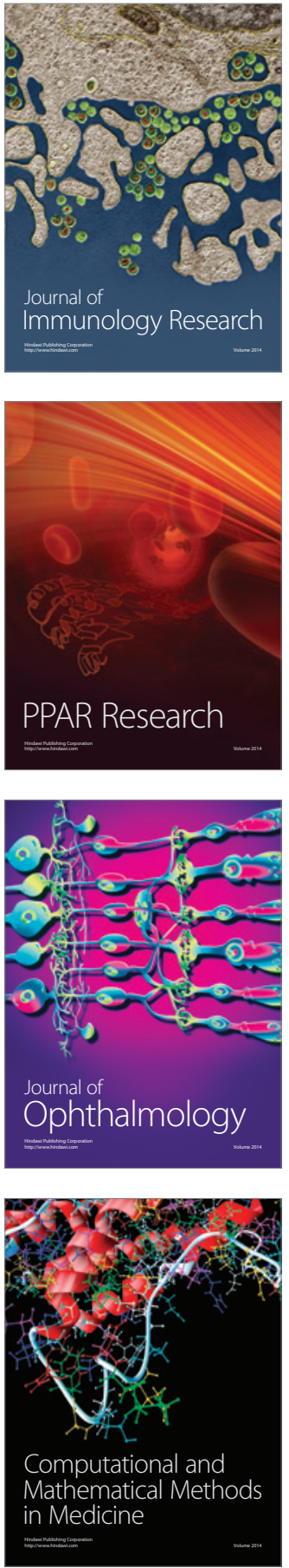

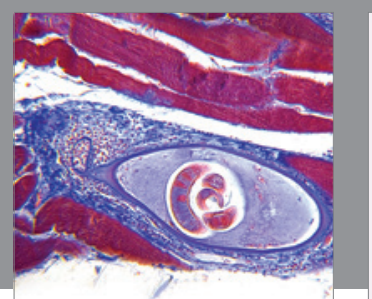

Gastroenterology Research and Practice

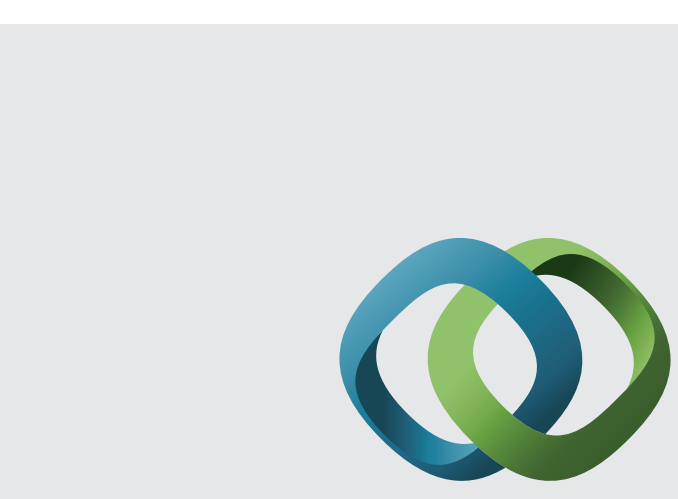

\section{Hindawi}

Submit your manuscripts at

http://www.hindawi.com
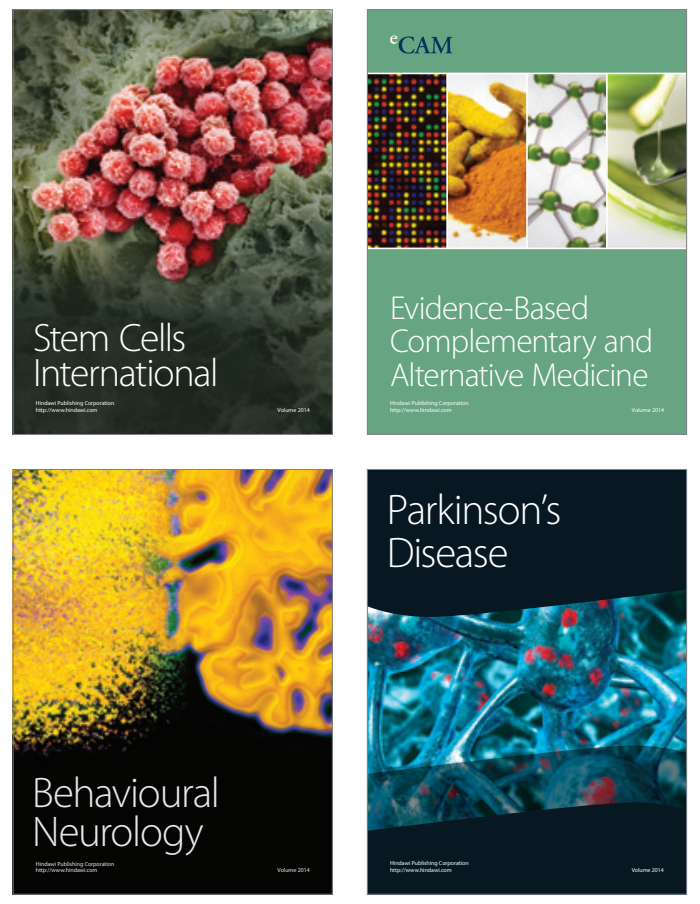
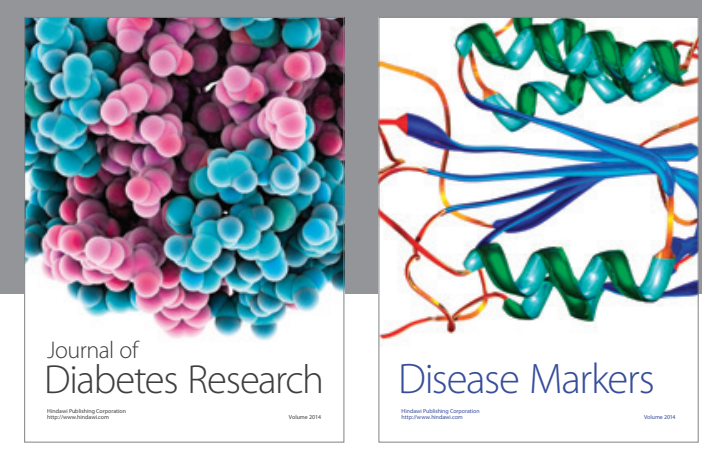

Disease Markers
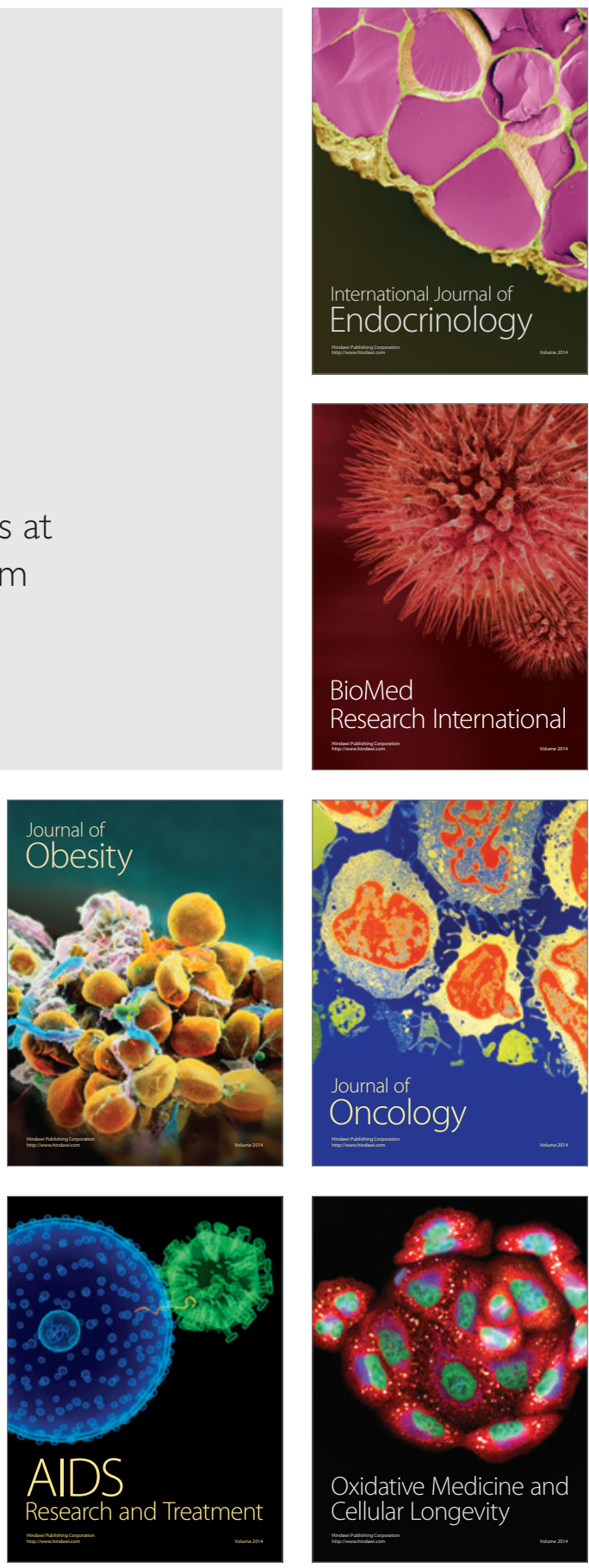